\title{
I.D.E.A: Inclusion, Diversity, Equity and Academia in Urology
}

\section{I.D.E.A: Inclusión, Diversidad, Equidad y Academia en Urología}

\author{
Martha Olivia Gómez-Alvarado, ${ }^{1}$ María Fernanda Chein-Vázquez. ${ }^{1}$
}

"Lo que tenemos que hacer es encontrar una manera de celebrar nuestra diversidad y debatir nuestras diferencias sin fracturar nuestras comunidades"

Hillary Clinton

Actualmente, en muchas universidades de México ingresan y se gradúan más mujeres que hombres de la carrera de medicina. Sin embargo, tras realizar una especialidad, la brecha de género se hace evidente y se refleja en que las mujeres siguen encontrando obstáculos para desenvolverse en el área de la salud. Por ejemplo, las mujeres tienen menor representación en investigaciones y menor acceso a los fondos asignados a éstas, menor representación en publicaciones, trabajo editorial y congresos; hay más dificultades para ocupar cargos jerárquicos en hospitales y sociedades académicas y profesionales; se les excluye frecuentemente en la toma de decisiones y del ejercicio del poder.

La urología no es una excepción. Sigue siendo un área dominada por hombres y las urólogas están más expuestas a un número mayor de micro y macro agresiones, así como a un trato menos igualitario. Las repercusiones de estas acciones pueden afectar el estado físico y mental de las doctoras, pueden implicar la decisión de permanecer o abandonar la vida académica e incluso que otras doctoras y estudiantes de medicina quieran ingresar al campo de la urología; al mismo tiempo, influyen en la reputación nacional e internacional de las sociedades académicas y en la comunidad científica en general.

Diversidad significa incluir personas con diferentes perspectivas, experiencias, opiniones, estilos de trabajo y expectativas. Se ha descrito que la diversidad en la medicina mejora el acceso a la salud por parte de grupos minoritarios, enriquece la relación médico-paciente y la toma de decisiones clínicas centradas en los pacientes. De hecho, algunas empresas internacionales con mujeres lidereándolas tienen mayor productividad económica.

${ }^{1}$ Coordinadoras de la Comisión de Género (2021-2023), Sociedad Mexicana de Urología, Ciudad de México, México. 


\section{I.D.E.A: Inclusion, Diversity, Equity and Academia in Urology. Gómez-Alvarado M. O., et al.}

Como comunidad urológica, necesitamos darnos cuenta del problema que existe y requerimos identificar las barreras que limitan la diversidad. Algunas empiezan desde el inicio de la carrera profesional a la par de la presión social por cumplir determinados roles y estereotipos.

En la Sociedad Mexicana de Urología, a través de la Comisión de Género, queremos invitarles a reconsiderar que la capacidad intelectual y la habilidad para adquirir destrezas profesionales y quirúrgicas no tienen relación con un género en particular; además las dife- rentes formas de acercarnos al paciente y de resolver conflictos pueden llegar a ser enriquecedoras para todos.

Queremos aprovechar la creatividad y la energía de todos los miembros de ésta y otras sociedades y asociaciones urológicas para alcanzar y mantener una equidad, para crear programas que lleven a una transición segura en donde todos podamos sentirnos en un ambiente de confianza y comprometernos a una continua autoevaluación y mejora, hombres y mujeres por igual. 